\title{
PAPÉIS DE BACO EM GEÓRGICAS II: FIGURAÇÃO POÉTICA, RELIGIOSIDADE E HISTÓRIA DO TEATRO ${ }^{1}$
}

\author{
Matheus Trevizam^ \\ Universidade Federal de Minas Gerais \\ Renata de Fátima Marçal Raimundo ${ }^{\star \star}$ \\ Universidade Federal de Minas Gerais
}

Vinum laetificatcor hominum

Psalm. 104.15

RÉSUMÉ: Dans ce texte, nous voudrions montrer, par des exemples effectifs du poème, comment Bacchus se revêts, au deuxième livre des Géorgiques de Virgile, de trois fonctions diverses. La première est l'indication de la vigne par le procédé poétique de la métonymie; l'autre, le rôle divin de porteur des dons naturels du raisin et du vin aux hommes; la dernière, enfin, le "prétexte" pour la proposition d'une petite histoire du théatre gréco-latin aux vers 376-396 de ce même livre.

MOTS-CLÉS: Géorgiques; Bacchus; métonymie; divinité; histoire du théâtre.

\footnotetext{
^ matheustrevizam2000@yahoo.com.br

$\star \star$ renatafmr@hotmail.com

${ }^{1}$ Este artigo conjunto se insere como produção vinculada ao projeto "Tradução integral e estudo compositivo do De arboribus, de Júnio Moderato Columela”, por mim orientado e agora desenvolvido na FALE-UFMG (agosto de 2010 a agosto de 2011) pela graduanda Renata de Fátima Marçal Raimundo, pelo Programa de Bolsas PIBIC/CNPq. Desenvolve-se, aqui, a exploração literária de um importante tópico - o "dionisismo" - em nexo direto com uma das obras estudadas na pesquisa (o livro II das Geórgicas virgilianas). Nossos sinceros agradecimentos à professora Tereza Virgínia Ribeiro Barbosa (Língua e Literatura grega - FALE-UFMG) pela generosa cessão de material bibliográfico referente à cultura helênica, bem como pelas úteis observações sobre o domínio teatral antigo.
} 


\section{Introdução}

O m Geórgicas II, segundo dos livros do conhecido poema didático de Virgílio, assistimos à concentração temática no grande tópico da arboricultura e, em específico, do cultivo das uvas. Se, por um lado, essa distribuição interna do peso dos vários tópicos possíveis encontra parcial confirmação na realidade econômica da Itália dos tempos do autor, ${ }^{2}$ não se pode deixar de ver na postura de fazer da mesma seção um "livro das videiras" motivações alheias ao plano meramente prático.

Referimo-nos, com os últimos dizeres, a um ponto atinente ao que a crítica especializada vem denominando, quando se refere a certo mecanismo construtivo amiúde empregado por Virgílio nesta obra, "seletividade". ${ }^{3}$ Trata-se do gesto do poeta de escolher, atento, os conteúdos agrários a adentrarem os versos das Geórgicas, tendo em vista, como hoje se aceita consensualmente, ${ }^{4}$ a destinação inicial do poema ao deleite literário de um público erudito e citadino: por jamais ter pretendido instruir verdadeiros camponeses para a lida agrária, ele evitou, assim, não só detalhar em excesso as técnicas rústicas, mas até abordar assuntos passíveis de enfastiar ou ferir o gosto do leitor romano em mira.

Isso significa a decisiva opção por favorecer o que lograsse produzir, ao longo das Geórgicas, a rentabilidade artística do poema. Em outras palavras, não nos encontramos, neste caso, diante de um simples tratado "agronômico" metrificado, como se tudo (e apenas) o que há de funcionalmente necessário numa obra técnica com tal natureza de fato

\footnotetext{
${ }^{2}$ Cf. Trevizam, M. Linguagem e interpretação na literatura agrária latina. Tese inédita, apresentada ao Programa de Pós-graduação em Linguística do IEL-UNICAMP para obtenção do título de Doutor. Campinas: UNICAMP, 2006, p. 19./ Cf. ainda Sirago, V. Storia agraria romana. I. Fase ascensionale. Napoli: Liguori, 1995.

${ }^{3}$ Cf. Dalzell, A. The criticism of didactic poetry. Essays on Lucretius, Virgil and Ovid. Toronto/ Buffalo/London: University of Toronto Press, 1996, p. 107.

${ }^{4}$ Cf. Dalzell, op. cit., p. 106: What Wilkinson has in mind when he says that the "Georgics" masquerades as a didactic poem is that the didactic purpose is not the main purpose, or, if it is, the message is not quite what it appears to be. It used to be suggested that the poem had an immediate practical application - that it was written to instruct the returning veterans whom Octavian had settled on the land. But this is no poem for the horny-handed sons of toil. Even more than the "De rerum natura", it was clearly designed to appeal to a sophisticated reader. The poem bristles with allusions to other writers.
} 
se encontrasse operante na constituição do texto. ${ }^{5}$ Contudo, a perda de pontos na informatividade técnica sempre é compensada em Virgílio por outros recursos, os quais se vinculam não só à força expressiva da poesia mesma, mas também às chances de expansão dos horizontes significativos para muito além dos cerrados limites dos antigos fundi rustici romanos...

Toca-se, aqui, em outro ponto fundamental da estrutura compositiva das Geórgicas: poema ostensivamente comprometido com a superficial veiculação de saberes em nexo com a agricultura cerealista (livro I), o plantio de árvores frutíferas ou não (livro II), a pecuária de grande e pequeno porte (livro III) e a criação de abelhas (livro IV), não deixa de construir-se em camadas de sentido, como se o visível (ou explicitamente enfatizado) também servisse de "suporte" para acoplarem-se, em estrato diverso, significados de mais vasto alcance. Lancelot Patrick Wilkinson, por sinal, em seu clássico estudo sobre o poema (1969), dedicou todo um capítulo à discussão das "ideias filosóficas, morais e religiosas" a ele incorporadas, ${ }^{6}$ em lúcida demonstração de que a obra de que nos ocupamos neste ensaio, em absoluto, não se esgota no campo estrito da preceituação rural.

Ao longo das páginas seguintes, atentando para os distintos empregos do nome de Baco no livro II das Geórgicas, bem como para sua relação complexa com o assunto da viticultura, intentaremos expor alguns motivos pelos quais a seleção do tópico das videiras se revestiu de especial interesse para um autor ocupado com a escrita de um poema didático sob os ditames do rendimento artístico. Por outro lado, a mesma concentração temática ainda possibilitou a Virgílio facilmente "abrir pontes" entre os saberes especializados da técnica "agronômica" e outros universos significativos conexos - como os da religiosidade e da discussão sobre as próprias origens da arte dramática antiga -, dotandolhe os versos de perceptível alargamento de ideias.

\footnotetext{
${ }^{5}$ Cf. Dalzell, op. cit., p. 107: Pliny had an axe to grind: the encyclopaedist had to prove himself superior in knowledge to the poet; and so his formidable work is full of rather dyspeptic criticisms of Virgil's omissions and misconceptions. But the charge of superficiality is none the less fair. Not only are essential points omitted, but the selection is itself strange. The horse was not an important animal on the Italian farm; yet it is given epic treatment, while the useful mule and donkey are passed over. ${ }^{6}$ Cf. Wilkinson, L. P. The “Georgics” of Virgil. A critical survey. Norman: University of Oklahoma Press, 1997, p. 121-152.
} 


\section{Baco e a figuração poética em torno de seu nome em Geórgicas II}

A videira, planta essencial para a economia e o quotidiano dos antigos, associa-se de imediato à figura de Dioniso/ Baco: ${ }^{7}$ como sabemos, trata-se do filho de Zeus e de Sêmele, princesa tebana abrasada pelo pai dos deuses quando este lhe aparecera, por seu desavisado pedido, sob a forma divina (e não antropomórfica). Como Sêmele já se encontrava grávida de Baco no momento de sua morte, Zeus tirou-o às pressas do ventre da mãe e coseu-o em sua coxa para que ele completasse seguro o ciclo de gestação. Depois de seu segundo nascimento, esse filho de Zeus passou por muitas aventuras, como a perseguição da ciumenta Hera quando de sua acolhida infantil na corte do rei Átamas, o resgate às sombras do Hades de sua mãe, a festiva descoberta do vinho junto às parreiras silvestres do monte Nisa, em companhia de Sêmele, das Ninfas e dos Sátiros...

Junito Brandão, ainda, pronunciando-se em específico sobre o caráter tardio da atestação dos ritos urbanos atenienses ao deus - séc. VI a.C. -, explica-o em função da própria natureza dionisíaca, pois que se trata de uma entidade em forte nexo com o universo rural, a vida das plantas e as potências geradoras cósmicas. ${ }^{9}$ Também não se pode esquecer, é óbvio, a face transgressora de Dioniso, por isso entendendo a temporária dissolução dos limites socialmente estabelecidos que caracterizava, na embriaguez e no êxtase, algumas ocasiões do culto a ele. Ao pronunciar-se, em específico, sobre as Anthesteria, festa primaveril do mês homônimo em honra de Baco, Walter Burkert escreveu, citando certo testemunho antigo (Phanodemos FGrHist $325 \mathrm{~F}$ 12):

${ }^{7}$ Cf. Brandão, J. S. Dicionário mítico-etimológico. Mitologia e religião romana. Petrópolis/

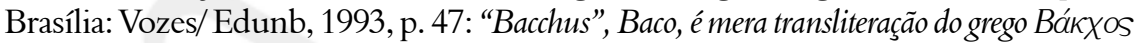
(Bákkhos). Este, como o verbo grego correspondente $\beta a \kappa \chi \in \dot{\epsilon} \in \sigma Ө$ a (bakkheúesthai) e o latino bacchari, "estar fora de si", derivado de "Bacchus", pode ser empregado, sobretudo na poesia, com a acepção passiva de "o que está agitado, em estado de embriaguez e exaltação, possuído do êxtase e do entusiasmo, do estro". Baco, segundo se mostrou no DIMEG., Vol. I, p. 151, não possui etimologia definida: talvez se trate de um empréstimo ao trácio. Acrescente-se, além do mais, que "Bákkhos",

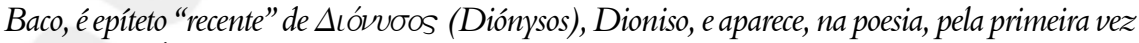
em Sófocles, Édipo Rei, 211. No que tange a Diónysos, o latim também o transliterou em Dionysus, Dioniso, que já está abonado na engraçadíssima comédia "Stichus" (Éstico), 661, de Plauto.

${ }^{8}$ Cf. Brandão, J. S. Mitologia grega. $18^{\text {a }}$. edição. Petrópolis: Vozes, 2009. Vol. II, p. 126-127.

${ }^{9}$ Cf. Brandão, op. cit., 2009, p. 128-129. 
At the sanctuary of Dionysos en limnais the Athenians used to mix the wine for the god from the jars which they transported along there and then taste it themselves... Delighted with the mixture, they celebrated Dionysos with songs, danced, and invoked him as the Fairflowering, the Dithyrambos, the Reveller and the Stormer (p. 237). ${ }^{10}$

Em Roma, segundo o contexto cultural que nos diz mais respeito a propósito da escrita das Geórgicas por Virgílio, o deus Baco foi logo associado a Liber Pater, ente do imaginário sacro itálico tido como responsável pelo germinar da semente e da seara. Em suas vinculações com cultos "licenciosos" de fertilidade agrária, ${ }^{11}$ por sinal, Líber contava inclusive com uma consorte (Líbera): segundo reportado por Santo Agostinho (De Ciu. Dei, 8, 3 e 7, 9), a dupla "favorecia a procriação e a fecundidade universais, libertando o sêmen no decurso da união sexual, projeção clara da semente que se planta no seio da Terra". ${ }^{12}$

Sincretismos greco-romanos à parte, no entanto, sabe-se que os ritos orgiásticos a Baco, em sua matriz de efetiva importação grega, não foram unanimemente difundidos ${ }^{13}$ ou bem aceitos em Roma. Aludimos

\footnotetext{
${ }^{10}$ Cf. Burkert, W. Greek religion. Translated by John Raffan. Cambridge, Mass.: Harvard University Press/ Basil Blackwell, 1985, p. 237.

${ }^{11}$ Cf. Brandão, op. cit., 1993, p. 206: Em certas partes da Itália, sobretudo no campo, as festas em honra do deus, denominadas "Liberalia", Liberálias, celebradas a 17 de março, comportavam elementos "licenciosos", quer dizer, que visavam à procriação, como a procissão de um falo que as matronas romanas tinham que coroar publicamente.

${ }^{12}$ Cf. Brandão, op. cit., 1993, p. 206.

${ }^{13}$ Cf. Brandão, op. cit., 1993, p. 47: Em Roma, aliás, diferentemente da Grécia, Baco não foi muito cultuado, convertendo-se mais num símbolo do próprio vinho e da inspiração poética, do estro provocado pelo néctar do deus. A respeito da muito mais ampla difusão dos ritos báquicos em solo helênico, por sinal, Walter Burkert posiciona-se assim (op. cit., p. 163): Among the Greek Dionysos festivals at least four types may be distinguished: the Anthesteria festival in the Ionic-Attic area, which is very directly concerned with wine-drinking, together with the Lenaia festival which precedes it; the Agrionia festival in the Dorian and Aeolic area, which is a festival of dissolution and inversion, with a women's uprising, madness, and cannibalistic fantasies; the rustic Dionysia with goat sacrifices and a phallos procession; and finally, the advent of Dionysos from the sea, Katagogia, the Great Dionysia, which were introduced in Athens at the sixth century. The intoxicated time of license seems common to all: sometimes it is the onset, sometimes the end of the period which is emphasized; sometimes it is goat sacrifices, sometimes bull sacrifices which predominate. In addition to the state festivals there are always the festivals, "orgia", celebrated by smaller groups, colleges and cult associations; often it is emphasized that these were trieteric, that is, celebrated every alternate year; secret cults, mysteries, developed at an early date.
} 
sobretudo aos eventos repressivos de 186 a.C., ao que tudo indica, motivados por excessos e más interpretações na adoção desses cultos entre os itálicos, jamais, de fato, apenas por se tratar de uma prática de origem estrangeira. ${ }^{14}$

De todo modo, Dioniso/ Baco/ Leneu ${ }^{15}$ faz-se muito evocado nos versos do livro II das Geórgicas quer por motivos afins, como anunciamos, à religiosidade, ou tematização de sua natureza sobrenatural, quer ao esboço da trajetória do drama desde as origens gregas até a entrada em solo itálico, ${ }^{16}$ quer, enfim, o que nos interessa mais para o presente foco, ao revestimento de elementos quotidianos do ambiente camponês por colorações poéticas em indelével elo com o tópico propiciatório da viticultura. Antes de passarmos à efetiva análise do verificável para a apropriação do nome do deus sob esse último viés, fazemos lembrar de que a cultura das uvas não era, em absoluto, a única forma de cultivo arbóreo ou frutífero em curso na península itálica antiga: a abordagem excessivamente sucinta das oliveiras, ${ }^{17}$ segundo feita

\footnotetext{
${ }^{14}$ Cf. Orlin, E. Religion and the "Res publica". In: Rüpke, J. A Companion to Roman religion. Malden, Mass./ Oxford, U.K./ Carlton, Australia: Blackwell Publishing, 2007, p. 64: Similar issues appear in the most famous religious incident of the Roman republic, the measures taken against followers of the Bacchic cult in 186 bce. In that year, rumors of criminal activity and sexual debauchery among the followers of Bacchus led the consuls to seek out the perpetrators; eventually over four thousand people throughout Italy were executed (Livy 39.8-19). Many features of this episode remain obscure, because Livy, our sole literary source, has included many details unlikely to be true in an effort to portray the repression as a reaction against the sudden infiltration of too many Greek elements into Roman worship.

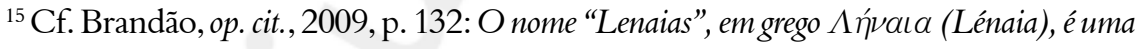
abreviatura já comum em Atenas, pois que a designação oficial da festa era Dioniso do Lénaion, local onde se erguia o mais antigo templo do deus e, mais tarde também, um teatro. (...) Se ainda se discute acerca da localização do "Lénaion", nada de muito concreto existe a respeito de sua etimologia. A

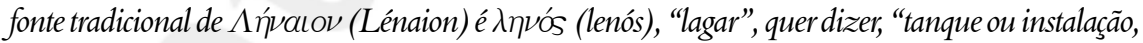
onde se espremiam as uvas para fabrico do vinho novo", mas a aproximação éde cunho popular.

${ }^{16}$ De fato, tragédia e comédia, assim formalmente estruturadas, adentram Roma a partir do séc. III a.C. pelo contato com o mundo grego (evocamos, nesses inícios de aculturação, os nomes arcaicos de Lívio Andronico - 284-204 a.C. - e de Névio - ?199 a.C.). Contudo, formas representativas burlescas itálicas, como os Mimos sicilianos e as Atelanas da Campânia, precederam cronologicamente o gênero cômico, seu correlato helênico imediato (cf. Poullain, P. La littérature latine: que sais-je? Paris: Presses Universitaires de France, 1948, p. 8-16).

${ }^{17}$ Cf. Dalzell, op. cit., 107: The opening lines of Book 2, which list the principal subjects to be discussed, give the impression that the olive and the vine will be accorded equal treatment. In fact the olive, so important to the Roman economy, is dismissed in six lines (2.420-5).
} 
no mesmo livro II, já demonstra, com as demais possíveis, a existência destacada de outras no solo pátrio do poeta. Entretanto, há sempre que se indagar, de forma semelhante à total omissão da suinocultura na parte pecuária do poema (o livro III) ${ }^{18}$ como seria possível obter algum mínimo rendimento poético da ampla exploração temática dos plátanos ou salgueiros, por exemplo...

Diante do tópico das videiras, pois, encontrou-se o poeta mais dotado de vias de escape para criar, haja vista, além da visceral associação da planta com um deus tão nuançado e rico de atributos quanto Baco, o próprio caráter passível de antropomorfização da mesma cultura. ${ }^{19}$ Embora pudéssemos eventualmente argumentar que a oliveira também conta com uma "patrona" divina, isto é, Palas, responsável por tê-la feito nascer na Acrópole de Atenas em disputa contra Posídon e o cavalo oferecido aos homens com um golpe de tridente, ${ }^{20}$ não se trata de um evento tão essencial à definição do caráter da deusa: ela, por sinal, em outras ocasiões, presenteara os mortais com vários dons distintos, igualmente fecundos em seus desdobramentos civilizadores. ${ }^{21}$

\footnotetext{
${ }^{18}$ Cf. Trevizam, op. cit., 2006, p. 158: Quanto aos porcos, sabemos que sua criação extensiva se constituía no principal meio disponível aos camponeses itálicos para a obtenção da carne: destinandose o gado bovino sobretudo ao transporte e os ovinos e caprinos a usos secundários (extração do leite e das fibras provenientes da pelagem), cabia aos suínos prestarem-se a um papel de grande utilidade alimentícia pela própria extensão da utilidade de seus corpos. Ocorre, porém, que não se trata de animais facilmente assimiláveis a temas poéticos: associados a atributos indesejáveis como a grosseria, tendem a permanecer às margens do universo representativo focalizado por esse poema didático.

${ }^{19}$ Lembramos tratar-se a videira de uma cultura proverbialmente trabalhosa para o homem, que não se pode deixar à própria sorte sem os riscos da infertilidade, por exemplo. Isso implica, assim, rendosas chances poéticas de mostrá-las em processo "educativo" contra a indisciplina natural de sua juventude (II 362ss) e postas sob as ordens severas de um general-agricultor (II 279-283).

${ }^{20}$ Cf. Commelin, P. Nova mitologia grega e romana. Tradução de Thomaz Lopes. Belo Horizonte: Itatiaia, 1983, p. 39: Um dos traços mais famosos da história de Minerva é sua diferença com Netuno para dar seu nome à cidade de Atenas. Os doze grandes deuses, escolhidos para árbitros, decidiram que aquele dos dois que produzisse a coisa mais útil à cidade the daria o nome. Netuno, de uma pancada do tridente, fez sair da terra um cavalo, Minerva, uma oliveira, o que the assegurou a vitória.

${ }^{21}$ Cf. Commelin, op, cit., p. 39: Ora conduz Ulisses em suas viagens, ora se digna ensinar às filhas de Pândaro a arte de se sobressair nos trabalhos próprios de mulheres, a representarflores e combates em obras de tapeçaria. Foi ela ainda que, com suas mãos, embelezou o manto de Juno. É ela, enfim, quem faz construir o navio dos Argonautas segundo seu desenho, e que coloca na popa o pau falante, cortado na floresta de Dodona, o qual dirigia a rota, advertindo perigos, indicando os meios de os evitar. Sob esta linguagem figurada é fácil reconhecer o leme do navio.
} 
No tocante à estrita exploração significativa dos benefícios da proximidade da planta com Baco, apontamos uma espécie de processo metonímico ${ }^{22}$ amiúde repetido em passagens que se podem, inclusive, catalogar em Geórgicas II. Os versos 37, 113, 228, 240 e 275, assim, correspondem sempre a ocasiões nas quais divisamos o emprego de um nome do deus (Bacchus, em latim) pelo da videira em si:

neu segnes iaceant terrae: iuuat Ismara Baccho

conserere atque olea magnum uestire Taburnum. ${ }^{23}$

...; denique apertos

Bacchus amat collis, Aquilonem et frigora taxi. ${ }^{24}$

(altera frumentis quoniam fauet, altera Baccho,

densa magis Cereri, rarissima quaeque Lyaeo) ${ }^{25}$

(frugibus infelix ea, nec mansuescit arando nec Baccho genus aut pomis sua nomina seruat) ${ }^{26}$

Collibus an plano melius sit ponere uitem, quaere prius. Si pinguis agros metabere campi,

\footnotetext{
${ }^{22}$ Cf. Tringali, D. Introdução à retórica. A retórica como crítica literária. São Paulo: Duas Cidades, 1988, p. 134: Se digo: "bebamos um Madeira", quero dizer um vinho fabricado na ilha da Madeira. Usei a palavra Madeira em lugar da palavra vinho. Na metonimia, uma palavra se usa em lugar de outra (Camões por "Lusíadas”), não por semelhança, mas porque há, entre ambas as coisas, uma relação de contiguidade. Há uma relação de vizinhança, de interdependência entre ambas as coisas, entre o vinho e a ilha da Madeira./ Considerando, ainda, certo epíteto de Dioniso [dendrítes = "(Dioniso) árvore", atestado em Plutarco II, 675], poder-se-ia, em determinados contextos, pensar no deus como, até, "encarnado" nas videiras/ outros objetos (cf. Frontisi-Ducroux, F. Le dieu-masque. Une figure de Dionysos d'Athènes. Paris: La Découverte, 1991, p. 37: L'image tantôt en faveur d'un arbre sommairement anthropomorphisé, tantôt dans le sens d'un pilier où s'incarnerait le dieu). Contudo, a geral indefinição da anuência ao sagrado nas Geórgicas, como adiante veremos, e nossa opção por restringir as presentes análises ao nível linguístico estrito justificam que não enveredemos aqui por tais vias especulativas.

${ }^{23}$ Geórgicas II 37-38: "Nem jazam inertes as terras: favorece plantar o Ísmaro/ com Baco e recobrir o grande Taburno com a oliveira" (todas as traduções do latim, salvo menção contrária, são de Matheus Trevizam e Renata de Fátima Marçal Raimundo). ${ }^{24}$ Geórgicas II 112-113: “; enfim, Baco/ ama as colinas abertas, o Aquilão e os frios os teixos”.

${ }^{25}$ Geórgicas II 228-229: "Pois uma traz proveito aos grãos, outra a Baco,/ a densa mais a Ceres, toda bem solta a Lieu".

${ }^{26}$ Geórgicas II 240-241: "Ela é nociva às searas, nem arando se amansa,/nem para Baco a linhagem ou, para os frutos, o nome conserva".
} 
densa sere: in denso non segnior ubere Bacchus. ${ }^{27}$

Sin tumulis adcliue solum collisque supinos, indulge ordinibus; (...)

A primeira ocorrência de metonímia em torno do nome de Baco desvela-nos duas localidades geográficas e duas culturas a elas associadas de forma excludente: assim, enquanto convém ao Ísmaro, monte trácio e mítica morada de Orfeu, o fecundo plantio de "Baco" (neu segnes iaceant terrae), cabem melhor ao Taburno, região do país samnita, na Itália, as oliveiras. Evidentemente, tais observações se prendem à ideia técnica, muitas vezes trazida à luz nas Geórgicas, de que nem sempre um dado tipo de solo se presta ao plantio indiscriminado de qualquer espécie vegetal. ${ }^{28}$ Deve-se, porém, observar como o emprego do nome do deus pelo da parreira furta a passagem ao âmbito da estrita tecnicidade, por se tratar de um recurso, embora nobilitador dos dizeres, acessório do ponto de vista da explícita referência ao objeto em jogo...

As ocorrências de "Baco" em v. 113, 228 e 240 manifestam clara semelhança com essa em importantes aspectos: de início, como vemos em todas, sempre se dá o próximo contraste entre um item que o contexto revela tratar-se da parreira "rebatizada" e alguma produção agrária diversa (Bacchus/ taxi, "Baco"/ "teixos" - v. 113, Baccho/ Lyaeo frumentis/ Cereri, "a Baco"/ "a Lieu"29 - "aos grãos"/ "a Ceres" - v. 228229, Baccho/ pomis, "a Baco"/ "aos frutos" - v. 239-240). Além disso, na segunda passagem transcrita, em que o tópico temático corresponde às condições climáticas favorecedoras do plantio, e na terceira, em que ele é substituído por observações atinentes aos tipos de solo em idênticas circunstâncias, ainda notamos a presença do mesmo mecanismo de escrita afim, está-se a ver, a atribuir a cada zona natural sua própria "vocação" produtiva.

\footnotetext{
${ }^{27}$ Geórgicas II 273-277: "Em colinas ou no plaino se é melhor plantar a videira/indaga antes: se medirás as terras de um rico campo,/ planta denso: em denso úbere, Baco não é mais preguiçoso./ Mas se um solo inclinado com elevações e colinas em ladeira,/cede espaço às filas".

${ }^{28}$ Em Geórgicas II 109ss, Virgílio nota: Nec uero terrae ferre omnes omnia possunt. - "Nem, na verdade, todas as terras podem dar tudo".

29 "Lieu” é epíteto do deus vinculado ao verbo grego $\lambda u ́ w$ ("eu liberto"), alusivamente ao caráter de demolidor das inibições que se associava à sua presença entre os homens [cf. Segal, C. Dionysiac poetics and Euripides' "Bacchae". Princeton: Princeton University Press, 1997, p. 21-22: In a metaphor which recurs throughout the play, he is "Dionysus the looser" (Lysios), he who "unbinds" what Pentheus has "bound up".].
} 
O último trecho transcrito em conjunto, por sua vez, furta-se a essa exata descrição significativa, pois nele não ocorre a opção por uma ou outra cultura: apenas, mesmo no entorno estendido, por como plantar unicamente as uvas. Essas, a saber, devem ser dispostas num campo rico com razoável concentração das mudas; mas, caso se plantem sobre quaisquer elevações (v. 276), seria antes recomendável dar espaço entre as fileiras de vinhas (v. 277). Devemos observar, a respeito dessa última ocorrência, que, embora não haja nela o contraponto de um termo vegetal paralelo a sustentar "Baco" em inequívoca acepção de "videira", o recurso à sinonímia basta para supri-lo em papel semelhante: referimo-nos à palavra uitem ("videira" - v. 273 -, flexionada no caso acusativo), pois, é óbvio, o que se achará nos campos de um ou outro modo - em terras baixas ou altas - e a produzir, almeja-se, bem será sempre e fisicamente o pé de uvas.

Seja como for, a observação detida dessas passagens dispersas do livro II das Geórgicas revela claros paralelismos construtivos que não julgamos casuais. Dito de outro modo, temos a nítida impressão, a propósito desses usos metonímicos do nome de Baco (ou de um seu epíteto, "Lieu", v. 229), de que a estruturação elocutória e o sentido de corresponder, em última instância, o deus à planta tendem a conjugarse ao longo de Geórgicas II com relativa estabilidade, exceção parcial dada, até certo ponto, à última ocorrência vista. Assim, furtamo-nos aqui à obviedade para de novo ressaltar, com outros, a cuidada e produtiva expressividade da dicção poética ${ }^{30}$ de Virgílio, sobretudo neste que alguns consideram o mais impecavelmente acabado de seus poemas.

\section{Baco e a religiosidade em Geórgicas II}

Como revela a leitura da assim chamada "literatura agrária latina", a religião constituiu parte relevante do quotidiano rural em Roma antiga. Desde Catão Censor e seu De agri cultura, ${ }^{31}$ passando pelo De re rustica

\footnotetext{
${ }^{30} \mathrm{Cf}$. Toohey, P. Epic lessons. An introduction to ancient didactic poetry. London/ New York: Routledge, 1996, p. 111: The second force impelling Virgil may have been literary emulation. His enthusiasm for Callimachean and Hellenistic poetics is often noted. Didactic epic was, as we have seen, a favoured mode of this school (Nicander, whom we looked at in Chapter 3, wrote didactic poetry on agriculture. Virgil may have taken his title from Nicander). It comes as no surprise that the younger Virgil should wish to record his encounter with this aspect of Alexandrian culture.

${ }^{31}$ Cf. Robert, J.-N. La vie à la campagne dans l'antiquité romaine. Paris: Les Belles Lettres, 1985, p. 304-305.
} 
de Varrão reatino ${ }^{32}$ até as próprias Geórgicas, ${ }^{33}$ o tradicional recurso dos agricultores latinos às forças sobrenaturais, com fins de favorecimento de suas atividades produtivas ou, ainda, de resguardo diante dos males da existência, deixou traços indeléveis nas páginas das obras mencionadas.

Há, no entanto, que ressaltar as devidas diferenças: se, em Catão, representante ainda arcaico e dogmático da mentalidade avoenga, os ritos, crenças, recomendações e preces refletem um estado da cultura de todo imbuído de escrúpulos do sagrado, ${ }^{34}$ o mesmo não se dá, exatamente, com os demais scriptores rerum rusticarum cujo nome citamos há pouco. Varrão, assim, com sua conhecida divisão entre os três tipos de religiosidade possível (a religião mitológica dos poetas, a religião depurada dos filósofos e a religião institucionalizada das Cidades), ${ }^{35}$ dificilmente poderia ser visto como crente à guisa dos maiores, o que significa que as menções aos deuses do vasto panteão antigo em seu $D e$ re rustica sobretudo correspondem ao "tom" tradicionalista ali favorecido pelo assunto agrário, sem verdadeiros intentos de aderir com ingenuidade.

Nas Geórgicas, o quadro não é menos complexo: alusões, invocações, preces e práticas religiosas abundam do começo ao fim do poema, ${ }^{36}$ sem, entretanto, que se possa fixar o grau exato da anuência do magister didático a elas. Posicionamentos críticos atuais, inclusive, têm ressaltado significativa instabilidade no endosso do poeta ao numinoso. ${ }^{37}$ Wilkinson, porém, tentara ao menos esboçar a problemática nos termos seguintes:

\footnotetext{
${ }^{32}$ Cf. Wilkinson, op. cit., p. $145 s s$.

${ }^{33}$ Geórgicas I 5-23 corresponde, entre muitos outros exemplos possíveis do sagrado no poema, à célebre invocação introdutória aos doze deuses rústicos.

${ }^{34}$ Cf. Trevizam, op. cit., 2006, p. 71.

${ }^{35}$ Em outra ocasião, pronunciamo-nos melhor sobre a teologia varroniana (cf. Trevizam, M. Religião romana nos livros iniciais do "De re rustica" varroniano. Nuntius Antiquus. Belo Horizonte, vol. IV, p. 55-57, 2009) - acesso on-line em 17 de abril de $2011<$ http://www.letras.ufmg.br/nuntius/index.asp?path=201082323547. asp\&title $=$ Volume $\% 20 \mathrm{IV}>$.

${ }^{36}$ Cf. supra nota 6 .

${ }^{37}$ Pronunciando-se sobre a difícil interpretação do divino, em seus nexos com o episódio da "Peste Nórica" do livro III, Monica Gale observou (Gale, M. Virgil on the nature of things. The "Georgics", Lucretius and the didactic tradition. Cambridge: University Press, 2000, p. 76-77): The progress of the disease is embodied in the nightmarish figure of the Fury Tisiphone, who emerges from the underworld, driving sickness and Fear before her and
} 
Cyril Bayley rightly called his book Religion in Virgil rather than The Religion of Virgil. What Virgil really thought, or rather felt, is very hard to determine. The Augustan poets may be ranged in ascending degrees of engagement - Ovid seems to have been interested and amused by the rites of the calendar, charmed and amused by the legends of the gods of mythology. (...) If asked to formulate a Credo, Virgil would probably have been reluctant; but, if pressed, he might have complied somewhat as follows: "I believe that there is a power working in the universe. Sometimes I call it simply natura, but with a more positive feeling than Lucretius, who uses the term rather as a personification of the way things work: it is a kind of life-force - quippe solo natura subest. (...) The gods of mythology, poetry and popular belief are embodiments of intimations men have had, at various levels, of the working of this power in different spheres. They represent the numinous feelings I have about the universe as a whole and about particular localities. I do not, of course, believe in their actual and separate existence as traditionally conceived; but their names have the value of accumulated associations, and any terrors they have once had have been dispelled by the progress of scientific thought, as exemplified in Lucretius. In my poems I have introduced the appropriate ones, hallowed by literary tradition: Daphnis, Pan and the Nymphs of Pastoral in the Bucolics; Bacchus and Ceres (representing the Greek Dionysus and Demeter), Pan and the Nymphs again, in the Georgics; the Olympians of epic and tragedy in the Aeneid. ${ }^{38}$

A existência de tais hesitações entre críticos tão abalizados, portanto, deve de imediato avisar-nos contra qualquer demasiada crença na "fé" simples de Virgílio/ magister didático diante dos deuses

growing grater day by day. Given the role played elsewhere by the Furies as instruments of divine vengeance, we might take these lines as more than metaphor, and see the plague as inflicted on the Norici for some unspecified crime. Once again, the end of the narrative seems at odds with its beginning. It is far from clear whether the plague is to be seen as a natural occurrence or as a divine punishment, and it is significant, I think, that we are in the same position as the Norici themselves in this respect. Since the sickness itself makes sacrifice and divination impossible, the usual channels of communication between human beings and the gods are no longer available. The Norici have no way of knowing what - if anything - their error has been, and no way of placating the gods. It is (as Lucretius would argue) because the gods are indifferent to human affairs, and have not in any case sent the plague? Or should we assume that the Norici have somehow deserved this punishment, or that the gods are simply arbitrary and unconcerned by human suffering? Once again, the poem in itself gives us no clear and unambiguous answer.

${ }^{38}$ Cf. Wilkinson, op. cit., p. 151-152. 
personificados do paganismo (como Baco). Isso não inviabiliza, no entanto, ao menos uma figuração de religiosidade, compreendendo-a como sua adesão ao visível - ainda que superficial - de determinadas práticas pias. Em II 2, então, o nome do deus, que se cita associado a um seu epíteto - "Pai Leneu", a partir de certo lugar de culto da divindade na Grécia antiga $-{ }^{39}$ dos v. 4 e 7 , insere-se no espírito da suposta crença do magister no poder "inspirador" do Nume para consigo: ${ }^{40}$

Hactenus aruorum cultus et sidera caeli: nunc te, Bacche, canam, nec non siluestria tecum uirgulta et prolem tarde crescentis oliuae. Huc, pater o Lenaee (tuis hic omnia plena muneribus; tibi pampineo grauidus autumno floret ager, spumat plenis uindemia labris), huc, pater o Lenaee, ueni, nudataque musto tinge nouo mecum dereptis crura coturnis. ${ }^{41}$

Evidentemente, seguindo uma prática literária de origens tão remotas quanto a épica homérica, o poeta opera, aqui, uma invocação ao ente sobrenatural (mais comumente, em outros contextos, as

\footnotetext{
${ }^{39}$ Cf. supra nota 15.

${ }^{40}$ Um exemplo antigo da atribuição do saber poético à inspiração sobrenatural das Musas corresponde aos afamados eventos do Hélicon, segundo narrado por Hesíodo em Teogonia, v. 22-34. Cf., a respeito dos efeitos desse arrebatamento divino, as palavras de Jaa Torrano no estudo introdutório que redigiu para sua tradução à mesma obra grega (Hesíodo. Teogonia. Estudo e tradução Jaa Torrano. São Paulo: Iluminuras, 1991, p. 21): A exortação "pelas musas comecemos a cantar" diz também que tenhamos nelas o princípio por que nos deixa guiar exprime ainda a vontade de que seja pela força delas que se cante. Não é nem a voz nem a habilidade humana do cantor que imprimirá sentido e força, direção e presença ao canto, mas é a própria força e presença das Musas que gera e dirige o nosso canto. - Assim o canto irrompe e se manifesta, a partir do nome que o nomeia em sua força numinosa, e os versos que seguem ao verso inicial são desdobramentos e explicitações do que neste nome ("Mousáon" = Pelas Musas) se diz no início e como o Princípio: o pronome "Elas" (vv. 2 e 22), a indicar sempre este nome-ser do Canto, retoma-o como sujeito das cláusulas descritivas e narrativas das atividades habituais deste Canto (i.e., das Musas) que pelo nome numinoso se evoca e se faz presente.

${ }^{41}$ Geórgicas II 1-8: "Até aqui, o cultivo dos campos e os astros do céu:/ agora a ti, Baco, cantarei, bem como, contigo, os renovos/ silvestres e a prole da oliveira a crescer tarde./ Para cá, pai Leneu (aqui tudo está cheio de teus/ dons; para ti floresce o campo carregado/ no pampíneo outono, e espuma a vindima em tinas cheias),/ para cá, pai Leneu, vem e as pernas nuas/ tinge comigo em mosto novo, tirando os coturnos".
} 
Musas) $)^{42}$ em vínculo de "patronato" para com o cultivo privilegiado ao longo do livro II das Gérgicas: note-se, a propósito, a menção aos dons báquicos (v. 4-5), ao "pampíneo outono" (v. 5) e à própria vindima (v. 6). Assim, por ora preterido em seu papel de ente homenageado pelos espetáculos dramáticos (dereptis... coturnis, "tirando... os coturnos" - v. 8), Baco deverá revestir-se de características rurais (por exemplo, tingindo "as pernas nuas em mosto novo", v. 7-8) e, simultaneamente, literárias, de instigador do canto (v. 2) que doravante se inicia... Por isso, ocorre insistente o convite ao deus para que se acerque - huc/ huc ("para cá"), v. 4 e 7 -, de modo a colaborar ficcionalmente (mecum, "comigo" - v. 8) com a condução dos labores práticos dos "camponeses"/ discipuli didáticos a ouvirem as lições dadas sob seus auspícios e... com o urdume deste canto a servir-lhes de veículo.

Os trechos seguintes do livro II das Gérgicas que tomamos para exemplo do recurso a Baco como ente divino e favorecedor do bomsucesso das práticas de cultivo apresentam, no cotejo com este primeiro, a diferença comum de se afastarem do gesto literário da invocação inspiradora. Dado, porém, como dissemos, o entrelaçamento, naquele caso, entre as funções "letrada" e de efetiva interferência divina no mundo material dos fazeres agrários - Baco tingirá com o magister didático as próprias pernas no ato de pisotear as uvas a fim de se obter o mosto! -, continuam-se ainda partilhando com o já divisado as características propiciadoras da vida e da fertilidade:

Sed grauidae fruges et Bacchi Massicus umor

impleuere; tenent oleae armentaque laeta. ${ }^{43}$

Ipse dies agitat festos fususque per herbam, ignis ubi in medio et socii cratera coronant, te libans, Lenaee, uocat pecorisque magistris uelocis iaculi certamina ponit in ulmo, corporaque agresti nudat praedura palaestra. ${ }^{44}$

\footnotetext{
${ }^{42}$ Ilíada I, 1-6: Canta-me, ó deusa, do Peleio Aquiles/ A ira tenaz, que, lutuosa aos Gregos/Verdes no Orco lançou mil fortes almas,/ Corpos de heróis a cães e abutres pasto:/ Lei foi de Jove, em rixa ao discordarem/ O de homens chefe e o Mirmidon divino (tradução de Odorico Mendes, p. 45).

${ }^{43}$ Geórgicas II 143-144: "Mas as searas carregadas e o humor mássico de Baco/ transbordaram; dominam as oliveiras e rebanhos alegres".

${ }^{44}$ Geórgicas II 527-531: "Ele mesmo celebra dias festivos e espalhado pela relva,/ quando no meio o fogo e os amigos coroam a cratera,/ fazendo libações invoca a ti, Leneu, e põe no olmeiro/ os certames do dardo veloz para os mestres do rebanho;/ desnuda os duros corpos no ginásio agreste".
} 
Os dois versos citados de início revelam-nos um pormenor do antológico excurso das Laudes Italiae: trata-se de mencionar, em contraste com alguns frutos "maus" das terras nos países estrangeiros, certos itens proveitosos que vicejavam na península. O vinho mássico, dom de Baco, ${ }^{45}$ era uma das mais finas variedades itálicas da bebida,${ }^{46}$ enquanto as oliveiras e os rebanhos, mesmo que prosaicamente, correspondem a elementos de que não podiam prescindir a economia e a vida diária dos romanos antigos.

O excerto seguinte, notamos, apresenta em miniatura um momento celebrativo qualquer entre rudes - mas felizes! - camponeses. Desse modo, contrapondo-se no excurso das Laudes ruris aos interesses funestos dos citadinos - magistraturas instigadoras da ambição desmedida, saques, guerras, riquezas ilícitas... -, os agricolae, além de trabalharem, por vezes interrompem alternadamente a labuta diária para divertir-se com bebida e folguedos. Como a bebida evocada na espécie de "simpósio" em que tomam parte é o vinho, gestos como a coroação $^{47}$ da cratera e o invocar a Leneu/ Baco presentificam, na passagem, a participação festiva da comunidade em algo a ultrapassar o mero âmbito humano: nesse sentido, a libação ${ }^{48}$ ao deus também o torna um convidado sobrenatural diretamente envolvido em tais comemorações.

\footnotetext{
${ }^{45}$ Julgamos que referir o vinho como dádiva do deus já se constitua num gesto imbuído de sacralidade na medida em que, de semelhantes reconhecimentos (também a propósito de outros dons rústicos, cf. invocação a vários entes sobrenaturais na prece inicial do livro I das Geórgicas), estrutura-se, nas obras da literatura agrária antiga, toda uma rede de crenças e ritos camponeses com fins propiciatórios. Ainda - como não interpretar assim? -, esse epíteto do vinho, justo numa sua variedade nobre, lisonjeia o propiciador sagrado por mostrá-lo generoso doador à humanidade, não de um "presente" qualquer.

${ }^{46}$ Marcial, Epigrammata III 49: Veientana mihi misces, ubi Massica potas:/ olfacere haec malo pocula, quam bibere. - "Misturas-me vinhos de Veios, ao beberes mássicos:/ prefiro cheirar esta bebida a tomar [aquela]".

${ }^{47}$ As coroas votivas herbais/ florais eram comumente associadas ao culto dos velhos deuses greco-romanos em suas imagens e oferendas (cf. Brandão, op. cit., 1993, p. 198). ${ }^{48}$ Sobre o significado marcadamente sacralizado das libações, cf. Burkert, op. cit., p. 71: Invocation and prayer are inseparable from libation: the cup is filled in order to pray, and the filled cup is passed to the guest with the invitation to pray in turn. In order to supplicate the gods aright at all, a libation is therefore required. When embarking on a voyage, wine is mixed in craters and then emptied into the sea from the stern of the ship, amid prayers and vows.
} 
A última passagem que transcrevemos a propósito do presente tópico analítico identifica-se com estes versos:

Quid memorandum aeque Baccheia dona tulerunt?

Bacchus et ad culpam causas dedit; ille furentis 455

Centauros leto domuit, Rhoetumque Pholumque et magno Hylaeum Lapithis cratere minantem. ${ }^{49}$

Em postura que se poderia considerar, justamente por se colocar no interior do "livro das videiras", algo sacrílega, os dons de Baco são preteridos nas vantagens diante de produtos citados pouco antes - como as matérias-primas de algumas árvores e o mel das abelhas -, por agora se considerarem, inclusive, favorecedores de litígios mortais entre embriagados. O episódio mítico evocado para sustentar esse inusitado ponto de vista corresponde às bodas de Pirítoo, o grande amigo de Teseu, e Hipodâmia: segundo narrado por Ovídio com maiores detalhes numa impressionante passagem de suas Metamorfoses, ${ }^{50}$ o vinho inflamara o desejo pelas fêmeas humanas nos centauros convidados à festa, de modo que a tentativa de rapto da noiva foi o estopim do enfrentamento mortal entre eles e seus anfitriões, os lápitas, de que o noivo era rei. Monica Gale, que analisa as Geórgicas "polifonicamente", ou seja, como resultado em aberto do diálogo entre várias posições ideológicas possíveis, vê nesse inesperado ponto do livro II, até, tons lucrecianos/ epicuristas de questionamento de certos produtos culturais, como a própria religião (religio), atacada com tanta veemência no De rerum natura: afinal, no quadro estruturador desta parte da obra, a viticultura e seus frutos, em princípio, deveriam opor-se ao caráter "caótico" de plantas demasiado exuberantes pela fertilidade espontânea, algo, vem-se aqui a descobrir, nem sempre permitido pela natureza mesma do deus em jogo...

\footnotetext{
${ }^{49}$ Geórgicas II 454-457: "Que de igualmente memorável trouxeram os dons báquicos?/ Baco também deu motivos à culpa: ele os enfurecidos/ centauros sujeitou à morte, Reto, Folo/ e Hileu, ameaçante com a grande cratera".

${ }^{50}$ Ovídio, Metamorfoses XII 210-535.

${ }^{51}$ Cf. Gale, op. cit., p. 72-75.
} 


\section{Baco e a história da cultura teatral antiga}

Já no início do livro II das Geórgicas, Virgílio aponta para as conexões que se crê, desde há muito, existir entre Dioniso e o nascimento da arte dramática antiga: referimo-nos, a propósito, ao v. 8 conforme citado anteriormente, no qual, como se lembram os leitores, o magister didático convida o deus a descalçar os coturnos para auxiliá-lo no trabalho apenas agrícola do pisoteio das uvas maduras. Como sabemos, esse tipo de calçado correspondia a parte da indumentária esperada dos antigos atores trágicos em cena, ${ }^{52}$ ao lado das máscaras e perucas e das vestes mais apropriadas a cada personagem.

Ora, Aristóteles, em passagem da Poética, associara a comédia a certos cortejos (báquicos) de caráter fálico:

Nascida, pois, de improvisações a princípio - tanto ela quanto a comédia, uma por obra dos que regiam o ditirambo, a outra por obra dos que regiam os cantos fálicos (grifo nosso), costume ainda hoje conservado em muitas cidades - a pouco e pouco a tragédia cresceu desenvolvendo os elementos que se revelavam próprios dela e, após muitas mudanças, estabilizou-se quando atingiu a natureza própria. ${ }^{53}$

Wilamowitz-Moellendorff, por sua vez, numa obra já velha de mais de um século, mas clássica para a compreensão da arte dramática grega, coloca-se semelhantemente a Aristóteles, atribuindo o nascimento da comédia - nem em todos os lugares assim chamada de início! $-{ }^{54}$ à soma de elementos oriundos das burlas sicilianas e dos cantos fálicos áticos, aos poucos assimilados ao espaço público ateniense

\footnotetext{
${ }^{52}$ Cf. Horácio. Arte Poética. In: Aristóteles; Horácio; Longino. A poética clássica. Tradução de Jaime Bruna. São Paulo: Cultrix, 2007, p. 57 (v. 80): (...), perfilharam-no os socos e os imponentes coturnos./ Em nota à mesma página, o tradutor explica: Socos, calçado próprio da comédia; coturnos, da tragédia.

${ }^{53}$ Cf. Aristóteles. Poética. In: Aristóteles; Horácio; Longino. A poética clássica. Tradução de Jaime Bruna. São Paulo: Cultrix, 2007, p. 23 (cap. IV)./Veja-se também explicação às origens da tragédia e da comédia, segundo tratadas por Aristóteles, em da Costa, L. M. A poética de Aristóteles. São Paulo: Ática, 2010, p. 16-17.

${ }^{54} \mathrm{Cf}$. von Wilamowitz-Moellendorff, U. Qu'est-ce qu'une tragédie attique? Traduit de l'allemand par Alexandre Hasnaoui. Paris: Les Belles Lettres, 2001, p. 26 : Nous ne

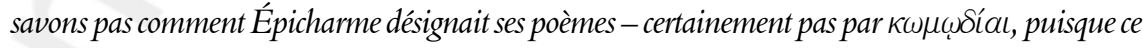
n'en était pas. C'est seulement à Athènes qu'on allait bientôt former ce mot sur le modèle de

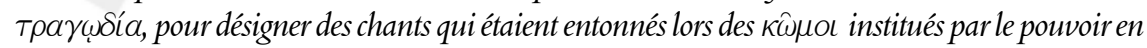
l'honneur de Dionysos, vers 465.
} 
e a certas diretrizes construtivas trágicas. ${ }^{55}$ Sobre as controversas origens do gênero trágico, propriamente, Grimal posiciona-se cauteloso, explicando tratar-se de uma forma artística com provável origem em Sícion, no Peloponeso: desse modo, teria cabido a Aríon (poeta do séc. VII a.C.) "inaugurá-lo" com a composição de uma "peça" a ter o herói Adrasto por protagonista. Tal "peça", ainda, revestira-se com grande verossimilhança de características líricas, pois Aríon foi, nota o erudito francês, um dos mais antigos líricos da Grécia. Ainda, ele aventa já haver ali não só um ditirambo cantado por um coro, mas, pelo menos, um ator - como em Ésquilo -, além de mencionar o testemunho do historiador Heródoto, segundo o qual o tirano de Sícion, Clístenes, "restituíra os coros a Dioniso". ${ }^{56}$

Também o nome desse último gênero dramático, em que se combinam duas sugestivas raízes gregas (trágos - "bode"/ oidé - "canto"), parece passível de remissões a Baco, como continua elucidando Grimal:

A hipótese mais provável é a que tem sido defendida frequentemente desde a Antiguidade: o tragôidos seria o poeta concorrendo para ganhar o prêmio da melhor tragédia; e este prêmio era (pensa-se) um bode, que o vencedor devia sacrificar imediatamente a Dioniso, para lhe agradecer a sua vitória. Sabe-se - isto pelo menos é seguro - que o bode era a vítima preferida do deus. Mas, se é assim, esta palavra não pode ser primitiva; só pode datar da época em que a tragédia foi integrada no ritual dionisíaco e, como observou corretamente Jacqueline de Romilly [A tragédia grega, Lisboa, Edições 70], isso só

\footnotetext{
${ }^{55} \mathrm{Cf}$. von Wilamowitz-Moellendorff, op, cit., p. 26-27: Il était en effet devenu courant que, lors de la fête de Dionysos, une ou plusieurs troupes d'hommes se réunissent, se déguisent - au début, afin de ne pas être reconnus - et entrent en cortège au son desfluttes dans le sanctuaire. Ils entonnaient un chant phallique en l'honneur de la divinité et haranguaient le peuple, rassemblé pour la fête religieuse et pour la tragédie, en un discours plein de vociférations, qui portait sur les intérêts du jour

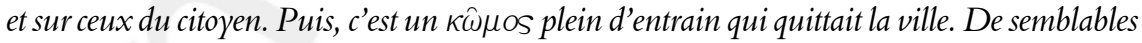
cortèges se déchainnaient certains soirs dans les ruelles, mais ils n'avaient pas le caractère solennel du $\kappa \hat{\omega} \mu \mathrm{os}$, car le cortège phallique faisait partie intégrante de la fête religieuse: c'est la raison pour

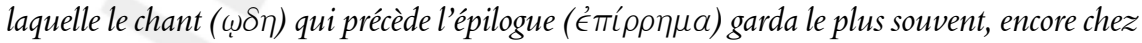
Aristophane, un caractère religieux. Il est fort possible que, déjà à l'époque des représentations spontannées, un ou deux orateurs isolés soient entrés en scène et aient interrompu les chants par quelque scène amusante. Mais, même si ce genre de choses s'est produit, le modèle de la tragédie vers lequel tout le dispositif théatral s'orienta lorsque la comédie fut organisée de façon officielle, n'en restait pas moins déterminant.

${ }^{56}$ Cf. Grimal, P. O teatro antigo. Tradução de António M. Gomes da Silva. Lisboa: Edições 70, 2002, p. 26.
} 
aconteceu "quando as improvisações religiosas, de que ela acabaria por sair, foram entregues e reorganizadas por uma autoridade política apoiada no povo". Assim, a instituição dos concursos de tragédias e o advento do próprio gênero no ciclo das festas da cidade seriam o resultado de duas causas interligadas: uma causa literária, que foi a descoberta por um poeta genial (sem dúvida Téspis) das possibilidades do gênero e, ao mesmo tempo, uma causa política, o desejo de os tiranos darem ao povo festas em que se forjaria a unanimidade da cidade. ${ }^{57}$

A passagem do livro II das Geórgicas mais em nexo com a temática teatral, porém, corresponde aos v. 376-396, em que elementos díspares se entrelaçam de maneira complexa:

Frigora nec tantum cana concreta pruina, aut grauis incumbens scopulis arentibus aestas, quantum illi nocuere greges durique uenenum dentis et admorsu signata in stirpe cicatrix. Non aliam ob culpam Baccho caper omnibus aris caeditur et ueteres ineunt proscaenia ludi, praemiaque ingeniis pagos et compita circum Thesidae posuere atque inter pocula laeti mollibus in pratis unctos saluere per utres. Nec non Ausonii, Troia gens missa, coloni uersibus incomptis ludunt risuque soluto, oraque corticibus sumunt horrenda cauatis, et te, Bacche, uocant per carmina laeta tibique oscilla ex alta suspendunt mollia pinu.

Hinc omnis largo pubescit uinea fetu, complentur uallesque cauae saltusque profundi et quocumque deus circum caput egit honestum. Ergo rite suom Baccho dicemus honorem carminibus patriis lancesque et liba feremus; et ductus cornu stabit sacer hircus ad aram pinguiaque in ueribus torrebimus exta colurnis. ${ }^{58}$

\footnotetext{
${ }^{57}$ Cf. Grimal, op. cit., p. 28.

${ }^{58}$ Geórgicas II 376-396: "Não tanto os frios congelados com a branca geada,/ ou o pesado verão pesando sobre rochas secas,/ quanto a prejudicaram os rebanhos, o veneno do cruel/ dente e a cicatriz deixada num tronco mordido./ Não por outra culpa, em todos os altares um bode a Baco/se sacrifica, adentram velhos espetáculos os proscênios,/ recompensas aos talentos em torno das aldeias e encruzilhadas/ propuseram os Tesidas e, entre as taças, alegres/ nos doces prados saltaram por odres untados./ Também os colonos ausônios, gente mandada de Troia,/ brincam
} 
Tomando como pretexto para de novo abordar esses assuntos, anunciados desde o início deste livro, como vimos, o caráter nocivo da mordida dos rebanhos para a "saúde" dos ramos de videira, Virgílio desenvolve em seguida o tópico do sacrifício caprino a Baco, como se o deus se regozijasse mais com essa vítima específica pela desforra diante de um danoso inimigo de sua amada cultura. ${ }^{59}$ As explicações de Grimal transcritas há pouco, quanto ao bode por prêmio dos dramaturgos de maior talento, esclarecem-nos o motivo de o poeta dizer aqui adentrarem "velhos jogos os proscênios" (v. 381), pois se trata de evocar o espírito competitivo em pauta como possível motivação para as tragédias

com versos sem arte e com riso solto,/ tomam horrendas faces da cortiça escavada,/ a ti, Baco, invocam por alegres cantos, e a ti/ suspendem móbiles flexíveis de um alto pinheiro./ Então, todo o vinhedo floresce em abundante fruto,/ enchem-se os vales, as cavas do bosque profundo/ e onde quer que o deus tenha virado a nobre cabeça./ Assim, ritualmente diremos a Baco suas honras/ com pátrios cantos e levaremos vasos votivos e bolos; / há de postar-se ao altar um bode sacro levado pelos chifres,/e tostaremos gordas tripas em espetos de aveleira".

${ }^{59}$ Também Varrão relata esta explicação da preferência "vingativa" de Baco/ Líber pelo sacrifício dos bodes: De re rustica I 2, 18-20: Quaedam enim pecudes culturae sunt inimicae ac ueneno, ut istae, quas dixisti, caprae. Eae enim omnia nouella sata carpendo corrumpunt, non minimum uites atque oleas. Itaque propterea institutum dinersa de causa ut ex caprino genere ad alii dei aram hostia adduceretur, ad alii non sacrificaretur, cum ab eodem odio alter videre nollet, alter etiam uidere pereuntem uellet. Sic factum ut Libero patri, repertori uitis, hirci immolarentur, proinde ut capite darent poenas; contra ut Mineruae caprini generis nihil immolarent propter oleam, quod eam quam laeseritfieri dicunt sterilem: eius enim saliuam esse fructuis uenenum: hoc nomine etiam Athenis in arcem non inigi, praeterquam semel ad necessarium sacrificium, ne arbor olea, quae primum dicitur ibi nata, a capra tangi possit. "Pois certos animais são danosos e letais às culturas, como esses a que te referiste há pouco, as cabras: elas estragam todas as plantas novas ao pastar, especialmente as videiras e oliveiras. Por isso, então, determinou-se por razões diferentes que uma vítima da espécie caprina fosse levada ao altar de uma divindade e não fosse imolada junto ao altar de outra, pois uma pelo mesmo ódio não queria ver e a outra queria ver morrendo. Assim, deu-se que ao pai Líber, descobridor da videira, os bodes fossem imolados, de modo a serem punidos com a pena de morte; contrariamente, que nada da espécie caprina imolassem a Minerva por causa da oliveira, pois dizem que se torna estéril aquela que estragou: a saliva desses animais é venenosa para seu fruto; por essa razão, também em Atenas não são conduzidos para a Acrópole mais do que uma vez por ano para o sacrifício necessário, a fim de que a oliveira, que se diz ter nascido lá em primeiro lugar, não possa ser tocada pelas cabras" (tradução de Matheus Trevizam). 
ocorrerem. O dito na sequência imediata, sobre recompensas ${ }^{60}$ "aos talentos" propostas "em torno das aldeias e encruzilhadas" pelos atenienses (Thesidae, "descendentes de Teseu", v. 382-383), parece ter mais nexo com a face cômica do dionisismo, em alusão aos cortejos licenciosos do deus que percorriam a Ática em certas datas comemorativas. ${ }^{61}$ Ainda, o tempo dos kômoi coincidia, no ambiente helênico, com as "Dionísias rurais" festivamente aludidas em v. 383384, nas quais Baco também se pinta celebrado em meio a cânticos, embriaguez e jogos campesinos, como o de tentar equilibrar-se de pé sobre odres de vinho untados por fora...

De v. 385-386 em diante, início de colorações arcaicas - pois Ausonia correspondia a um velho nome da Itália, ${ }^{62}$ a lenda das origens troiana do povo de Roma era antiquíssima ${ }^{63}$ e os "versos sem arte" de 386 parecem aludir ao pesado ritmo Satúrnio da poética latina pré-helênica $-{ }^{64}$ Virgílio adentra as teatralidades pátrias. Nessa subseção, pois, não faltam o riso (v. 386), as feias máscaras de cortiça postas pelos camponeses

\footnotetext{
${ }^{60}$ Cf. Grimal, op. cit., p. 34: Parece também que tais "kômoi" tenham dado lugar a disputas (o que os gregos chamavam "agônes", lutas verbais) entre os participantes, divididos em dois campos. Os vencidos - enquanto os seus adversários, mais felizes, permaneciam na cidade onde festejavam iam em grupos pelas aldeias pedir que thes dessem de comer, assegurando que isso "traria felicidade" aos dadores.

${ }^{61}$ Cf. Grimal, op. cit., p. 32: Etimologicamente, a comédia é o “canto de ‘kômos”, o cortejo barulhento que, sobretudo na estação das vindimas, percorria as aldeias cantando e dirigindo gracejos licenciosos àqueles com quem se cruzava. Aristóteles testemunha que alguns autores faziam derivar esta palavra do termo grego "aldeia" ("kômê"), etimologia certamente errada, mas reveladora, contudo: no pensamento grego, a comédia aparecia integrada no foldore das aldeias, um fenômeno essencialmente rústico.

${ }^{62} \mathrm{O}$ dicionário latino-francês de Félix Gaffiot oferece, na entrada Auson, -onis, a definição primeira do nome de um filho de Ulisses, dizendo-o epônimo da Ausônia; essa, por sua vez, correspondia poeticamente (Virgílio, Eneida X 54) à Itália, a partir do nome arcaico de uma de suas regiões.

${ }^{63}$ Ela já fora, por exemplo, apropriada pelo poeta arcaico Névio, que a transformou num importante detalhe (cf. detalhado início da introdução de Antonio La Penna para uma tradução italiana da Eneida feita por Riccardo Scarcia - Virgilio. Eneide. Introduzione di Antonio La Penna, traduzione e note di Riccardo Scarcia. Milano: Rizzoli, 2002. Vol. I, p. 25): Nevio, elaborando il mito secondo le sue esigenze, inventò um soggiorno di Enea a Cartagine, e all' inimicizia insorta con Didone faceva risalire la causa delle guerre puniche: dunque mito e storia costituivano un blocco unico.

${ }^{64}$ Cf. Cardoso, Z. A. A literatura latina. São Paulo: Martins Fontes, 2003, p. 3-4: Pesado, longo e monótono, o verso satúrnio foi utilizado, em Roma, nos mais antigos cânticos de que se tem noticia.
} 
(v. 386), as invocações a Baco por meio de cantos alegres (v. 388) e o gesto de dependurar simbolicamente móbiles em árvores (v. 389). Segundo explicado por Wilkinson com remissão a outro erudito, ${ }^{65}$ tais elementos de festa, nos quais se imiscui Baco em fantasioso sincretismo com a cultura helênica das "Dionísias rurais", remetem-nos, na verdade, às Compitaliae peninsulares. Nessas datas - em que, sintomaticamente, jamais se sacrificava bode algum! -, os deuses cultuados, na verdade, não eram Dioniso/ Baco/ Liber Pater, mas os "Lares das encruzilhadas" (Lares Compitales). ${ }^{66}$

Os deuses itálicos assim chamados tinham-se por defensores das familiae - unidades correspondentes a todos os habitantes da casa sob a autoridade de cada Pater familias, mesmo os escravos $-{ }^{67}$ e de seu espaço físico de morada (neste caso, as terras do fundus rusticus pertencente ao dominus) contra toda a sorte de malefícios visíveis ou invisíveis. Os compita, no ambiente rural, eram pontos sagrados de culto aos Lares, e vinham a identificar-se com o local de intersecção entre os limites (limites) das várias propriedades contíguas; neles, ainda, encontravam-se usualmente pequenos altares ao ar livre aonde todos, livres ou não, traziam oferendas votivas como bolos rituais, jugos de arado partidos os quais representavam o fim ditoso dos trabalhos agrícolas àquelas alturas de inícios de janeiro -, faixas e os móbiles - oscilla - a que alude Virgílio em v. 389. No último caso, em número exato correspondente ao dos habitantes da uilla rustica, os objetos repunham, sob a forma de bolas de lã ou, propriamente, de pequenos bonecos estilizados, a própria presença dos membros de cada familia, em gesto solicitador da proteção divina para todos ali "compreendidos". 68

Mas, fundamentalmente, os ritos, preces e oferendas aos Lares Compitales eram ainda acompanhados, como bem lembrou Jean-Noël Robert, de fortes elementos de distensão social:

Les Compitalia sont également l'occasion de s'amuser. Ces rassemblements populaires se déroulent un peu dans une atmosphère de foire. Des sociétés d'esclaves et d'affranchis (collegia compitalicia) se forment. On y applaudit des acteurs et acrobates divers dont on dévine

\footnotetext{
${ }^{65}$ Cf. Wilkinson, op. cit., p. 149-150.

${ }^{66}$ Cf. Robert, op. cit., 305-307.

${ }^{67}$ Cf. de Coulanges, F. A cidade antiga. Tradução de Fernando Aguiar. São Paulo: Martins Fontes, 2004, p. 28-34.

${ }^{68}$ Cf. Robert, op. cit., p. 306.
} 
aisément qu'ils répandaient parmi les esclaves un esprit de licence et, comme le dit Horace, de "rustiques sarcasmes ». Parfois même souffle un vent de révolte parmi les esclaves et César, puis Auguste, interdirent ces sociétés et ces jeux. Auguste rétablit ensuite le culte des Lares Compitales en y adjoignant celui de son Genius et décida qu'on le célebrait deux fois l'an, en mai et en août, mais les fêtes du début janvier n'en continuèrent pas moins à se dérouler, marque de la force de la tradition religieuse à la campagne. ${ }^{69}$

O caráter alegre e "carnavalesco" das Compitalia, sem dúvida, bem como a existência de jogos teatrais na hora de festejá-las na Itália, devem ter inspirado em Virgílio os paralelos com as "Dionísias rurais" gregas, mesmo, como vimos, se Baco não correspondia factualmente ao "homenageado" desta vez, e há flagrantes pontos destoantes em um e outro contexto ritualístico (haja vista até a alusão, em ambiente religioso itálico, a um "bode sacro" em v. 395...). Ao final, porém, acreditamos em que a confluência entre essas duas festividades "nacionais" de novo ocorre, pois, da mesma forma que Dioniso de início fora um ente da fertilidade vegetal entre os camponeses helenos, ${ }^{70}$ sua força propiciatória, depois de agraciado com cânticos e mascaradas, também se derramará sobre os rústicos "ausônios" sob a notável forma do crescimento abundante dos vinhedos (v. 390-391).

Por último, fazemos notar, apesar de nossa presente separação, para os fins estruturais deste artigo, entre as funções báquicas religiosas e de historicização sobre o teatro, a impossibilidade de operar plenamente semelhante corte: por um lado, então, se a maioria das teorias antigas e modernas a respeito do berço da arte dramática no Ocidente está correta, todo e qualquer nexo entre Baco e os principais gêneros dramáticos gregos (inclusive o drama satírico, de que aqui não tratamos por motivos de especificidade focal) deve por força passar pelo viés da sacralidade. Além disso, segundo textualmente documentado na passagem virgiliana que tomamos para derradeiro objeto de análise, o poeta latino vincula o desempenho de performances rústicas a também envolverem mascaradas, cantos e risos a fantasiosas homenagens divinas cujo fim almejado, em última instância, não se esgota no mero prazer dos viticultores da Itália, mas projeta-se para captar as boas graças báquicas, a derramar-se em exuberância de vinhas...

${ }^{69}$ Cf. Robert, op. cit., p. 306-307.

${ }^{70}$ Cf. supra nota 9. 
Isso dito, damo-nos por modestamente quites se algo se pôde dizer quanto ao rendoso "suporte" temático da cultura das uvas para os fins a que Virgílio votou as tantas evocações de Baco ao longo do livro II de suas Geórgicas. Nesse sentido, pois, tê-la privilegiado nesta parte de seu poema didático da terra implicou, além do quase automático recurso à metonímia, também as chances de expandir, "por acoplamento temático", o campo de visão do leitor da mera tecnicidade agrícola para os planos do numinoso e das raízes teatrais.

\section{Referências}

ARISTÓTELES. Poética. In: ARISTÓTELES; HORÁCIO; LONGINO. A poética clássica. Trad. Jaime Bruna. São Paulo: Cultrix, 2007, p. 17-52.

BRANDÃO, J. S. Dicionário mítico-etimológico. Mitologia e religião romana. Petrópolis/ Brasília: Vozes/ Edunb, 1993. Mitologia grega. 18. ed. Petrópolis: Vozes, 2009. Vol. II.

BURKERT, W. Greek religion. Translated by John Raffan. Cambridge, Mass.: Harvard University Press/ Basil Blackwell, 1985.

CARDOSO, Z. A. A literatura latina. São Paulo: Martins Fontes, 2003.

CATO; VARRO. On agriculture. With an English translation by H. D. Hooper. Cambridge, Mass.: Harvard University Press, 2006.

COMMELIN, P. Nova mitologia grega e romana. Trad. Thomaz Lopes. Belo Horizonte: Itatiaia, 1983.

da COSTA, L. M. A poética de Aristóteles. São Paulo: Ática, 2010.

de COULANGES, F. A cidade antiga. Trad. Fernando Aguiar. São Paulo: Martins Fontes, 2004.

DALZELL, A. The criticism of didactic poetry. Essays on Lucretius, Virgil and Ovid. Toronto/ Buffalo/ London: University of Toronto Press, 1996.

FRONTISI-DUCROUX, F. Le dieu-masque. Une figure de Dionysos d'Athènes. Paris: La Découverte, 1991.

GAFFIOT, F. Dictionnaire latin-français. Paris: Hachette, 1934.

GALE, M. Virgil on the nature of things. The "Georgics", Lucretius and the didactic tradition. Cambridge: University Press, 2000.

GRIMAL, P. O teatro antigo. Trad. António M. Gomes da Silva. Lisboa: Edições 70, 2002. HESÍODO. Teogonia. Estudo e tradução Jaa Torrano. São Paulo: Iluminuras, 1991.

HOMERO. Iliada. Trad. Odorico Mendes. Cotia/ Campinas: Ateliê Editorial/ UNICAMP, 2008.

HORÁCIO. Arte Poética. In: ARISTÓTELES; HORÁCIO; LONGINO. A poética clássica. Trad. Jaime Bruna. São Paulo: Cultrix, 2007, p. 53-68.

JONES, P. V.; SIDWELL, K, C. Reading Latin. Grammar, vocabulary and exercises. Cambridge: University Press, 1986. 
LIDDLE, H. G.; SCOTT, R. Abridged Greek-English lexicon. Oxford: University Press, 1935.

MAFRA, J. J. Sobre as origens gregas da comédia. In: MAFRA, J. J. Cultura clássica grega e romana. Belo Horizonte: PucMinas, 2010, p. 137-152.

ORLIN, E. Religion and the "Res publica". In: Rüpke, J. A Companion to Roman religion. Malden, Mass./ Oxford, U.K./ Carlton, Australia: Blackwell Publishing, 2007, p. 58-70

OVIDIO. Metamorfosi. Con un saggio di Italo Calvino, traduzione di Piero Bernardini Marzolla. Torino: Einaudi, 1994.

POULLAIN, P. La littérature latine: que sais-je? Paris: Presses Universitaires de France, 1948.

ROBERT, J.-N. La vie à la campagne dans l'antiquité romaine. Paris: Les Belles Lettres, 1985.

SEGAL, C. Dionysiac poetics and Euripides' "Bacchae". Princeton: Princeton University Press, 1997.

SIRAGO, V. Storia agraria romana. I. Fase ascensionale. Napoli: Liguori, 1995.

TOOHEY, P. Epic lessons. An introduction to ancient didactic poetry. London/ New York: Routledge, 1996.

TOSI, R. Dicionário de sentenças latinas e gregas. Trad. Ivone Castilho Benedetti. São Paulo: Martins Fontes, 2000.

TREVIZAM, M. Linguagem e interpretação na literatura agrária latina. Tese inédita, apresentada ao Programa de Pós-graduação em Linguística do IEL-UNICAMP para obtenção do título de Doutor. Campinas: UNICAMP, 2006.

. Procedimentos retóricos e construção dos sentidos nas "Laudes Italiae" de Varrão e Virgílio. In: ASSUNÇÃO, T. R.; FLORES-Jr., O.; dos SANTOS, M. M. (Org.). Ensaios de Retórica Antiga. Belo Horizonte: Tessitura, 2010, p. 135-143.

. Religião romana nos livros iniciais do "De re rustica" varroniano. Nuntius

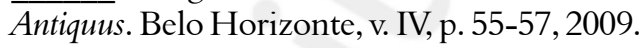

TRINGALI, D. Introdução à retórica. A retórica como crítica literária. São Paulo: Duas Cidades, 1988.

VIRGILE. Géorgiques. Texte traduit par E. de Saint-Denis. Paris: Les Belles Lettres, 1998.

.Eneide. Introduzione di Antonio La Penna, traduzione e note di Riccardo Scarcia. Milano: Rizzoli, 2002. Vol. I.

von WILAMOWITZ-MOELLENDORFF, U. Qu'est-ce qu'une tragédie attique? Traduit de l'allemand par Alexandre Hasnaoui. Paris: Les Belles Lettres, 2001.

WILKINSON, L. P. The "Georgics" of Virgil. A critical survey. Norman: University of Oklahoma Press, 1997. 